\title{
Medikamentell behandling av nevropatisk smerte
}

\author{
Nevropatisk smerte er vanskelig å diagnostisere og behandle. Flere \\ medikamenttyper er førstevalg, men det kan ofte være nødvendig med \\ en individuell vurdering og titrering av doser. Både smertetype og even- \\ tuelle ledsagende symptomer har betydning for valg av legemiddel.
}

Internasjonale smertemedisinske miljøer har de siste årene kommet med prinsipielt sammenfallende retningslinjer for medikamentell behandling av nevropatisk smerte hos voksne. På bakgrunn av forfatternes erfaring innen feltet har vi gjort et skjønnsmessig utvalg av litteratur som enten beskriver retningslinjene $(1-5)$ eller sammenlikner dem (6-8). Forskjellene mellom retningslinjene er hovedsakelig om nevropati defineres $\mathrm{i}$ en eller flere behandlingskategorier, om legemidler rangeres og om det beskrives en trinnvis medikamentell behandlingsalgoritme (6-8). Den øvrige utvalgte litteraturen oppsummerer ulike typer nevropatisk smerte, smertebeskrivelse og grunnlaget for anbefaling av legemidler fra kliniske studier $(9-14)$.

\section{Nevropatisk smerte}

Nevropatisk smerte defineres som smerte som oppstår som en direkte konsekvens av en lesjon eller en sykdom som affiserer det sentrale eller perifere somatosensoriske nervesystem (9). Dette i motsetning til nociseptive smerter som er forårsaket av skade på annet kroppsvev, som for eksempel ved kuttskader, inflammasjon, leddsmerter og postoperativ innvollssmerte $(9,10)$. Nociseptive smerter er ofte verkende, skarpe eller bankende, mens nevropatiske smerter kan ha en brennende, kriblende karakter, ofte ledsaget av overømfintlighet for berøring, kulde og varme. Perifer nevropatisk smerte ses ved tilstander som postherpetisk nevralgi, diabetesnevropati, ikke-diabetisk polynevropati, kreft og etter cellegift (6). Tynnfibernevropati (skade av tynne umyeliniserte eller myeliniserte fibre som leder smerte, temperatur og autonome impulser) kan gi nevropatiske smerter i ekstremitetene og autonome symptomer. Kompresjon av nerver samt lesjoner etter traume og kirurgi kan også gi perifer nevropatisk smerte.

Sentral nevropatisk smerte kan for eksempel ses etter hjerneslag, ved multippel sklerose og etter ryggmargsskade (10). Vanligvis vil man ved nevropatisk smerte finne sensibilitetsforandringer ved klinisk nevrologisk undersøkelse, unntatt ved tynnfibernevropati. Typiske funn er nedsatt smerte- respons (hypoalgesi), nedsatt berøringssans (hypoestesi), smerterespons på ikke-smertefulle stimuli (allodyni), økt eller endret smerterespons (hyperalgesi eller dysestesi) og endret sensibilitet for temperatur. Sensibilitetsforandringer kan imidlertid også ledsage nociseptive smerter som ledd $\mathrm{i}$ en sekundær sentralnervøs sensitisering (9, 10). Karakteristisk for nevropatisk smerte er spontan vedvarende smerte med forverring under og etter fysisk aktivitet og ved eksponering for kulde. Enkelte pasienter opplever smerte som provoseres av lett berøring, kulde eller varme på huden, når de har på seg klær, har dyne over seg eller ved støt mot smerteutsatt område (10).

Trigeminusnevralgi er eksempel på en nevropatisk smertetilstand som kjennetegnes av smerteanfall ved utløsende stimuli. Nevropatisk smerte beskrives av pasientene på mange forskjellige måter, for eksempel som brennende, jagende, stikkende, anfallsvis, lammende, sjokkaktig, dyp, murrende, mauraktig, kløende og lynende. Grundig anamnese og verktøy som smerteskala og symptomkart er viktig i utredningen, men pasientenes beskrivelser overlapper ofte med andre smertetilstander og kan ha lav diagnostisk verdi. Nevropatisk smerte er ikke uvanlig, og utredning av tilstanden er tidligere utførlig beskrevet i Tidsskriftet (10). Risiko for redusert livskvalitet tilsier lav terskel for henvisning til nevrolog og nevrofysiolog for å bestemme hvilken type nevropati som foreligger og eventuell medikamentell behandling. Dette også fordi pasienter med nevropatiske smerter ofte får feil legemidler eller lavere dose sammenliknet med det som har vist effekt i kliniske studier (10).

\section{Kliniske studier}

I de fleste randomiserte studier over smertefull nevropati har man konsentrert seg om diabetesnevropati og postherpetisk nevralgi (6). Endepunktene er ofte smertereduksjon (målt med smerteskala) eller effekt på søvnkvalitet, stemningsleie, generelt funksjonsnivå og livskvalitet. Det er uavklart om resultatene er overførbare til andre nevropatiske smertetilstander, og ettersom oppfølgingstiden i studiene ofte er kort, er det usikkert om
Geir D. Slapø

Oslo Nevroklinikk

\section{Jan Schjøtt}

jan.didrik.schjott@helse-bergen.no

Seksjon for klinisk farmakologi

Laboratorium for klinisk biokjemi

Haukeland universitetssykehus

\section{HOVEDBUDSKAP}

Flere medikamenttyper kan være førstevalg ved nevropatisk smerte

Ved valg av medikament bør man ta hensyn til eventuelle ledsagende symptomer som søvnløshet, angst og depresjon

Den medikamentelle behandlingen bør tilpasses den enkelte pasient 


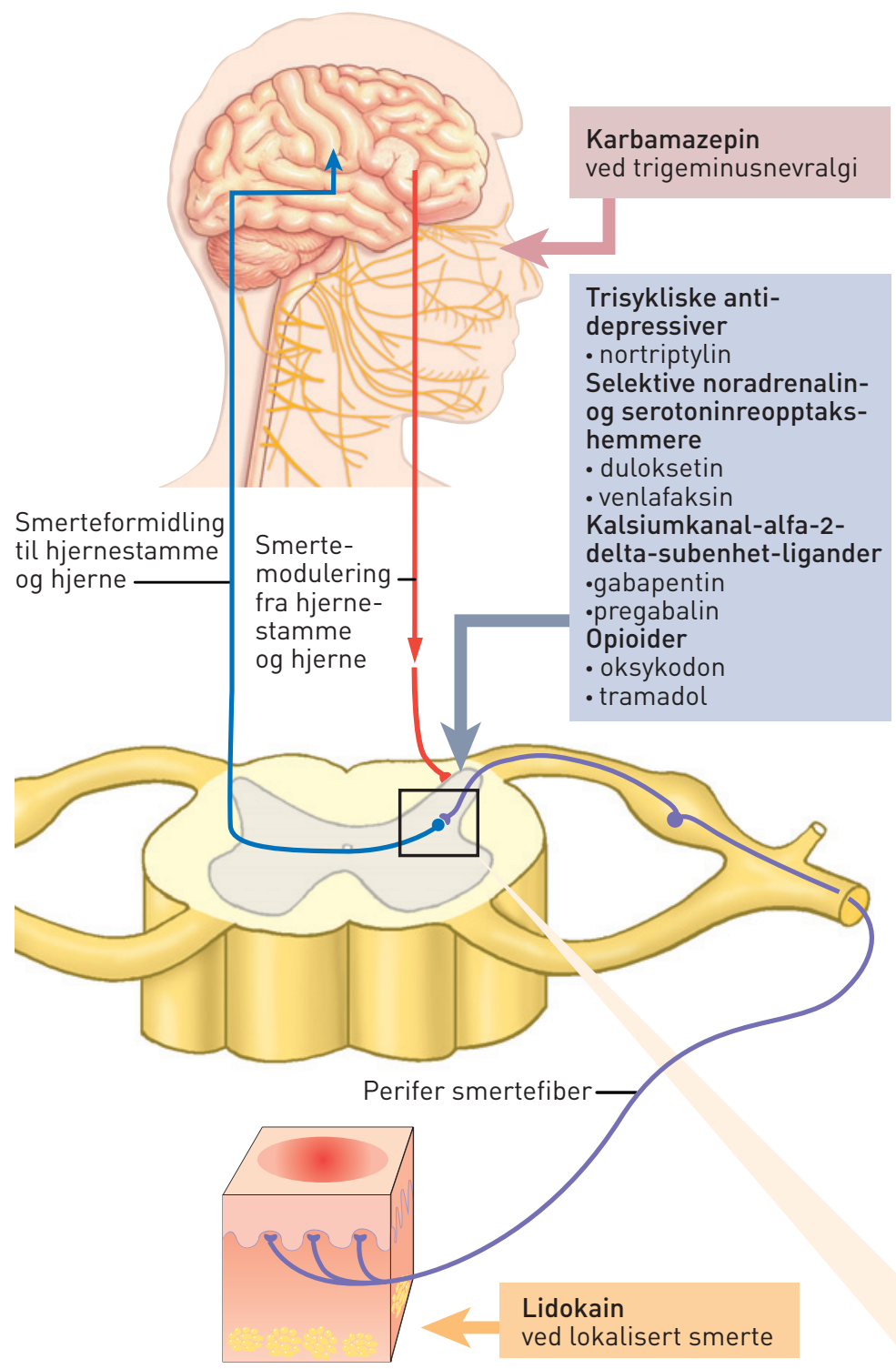

\section{1. ordens synapse i ryggmargens bakhorn}

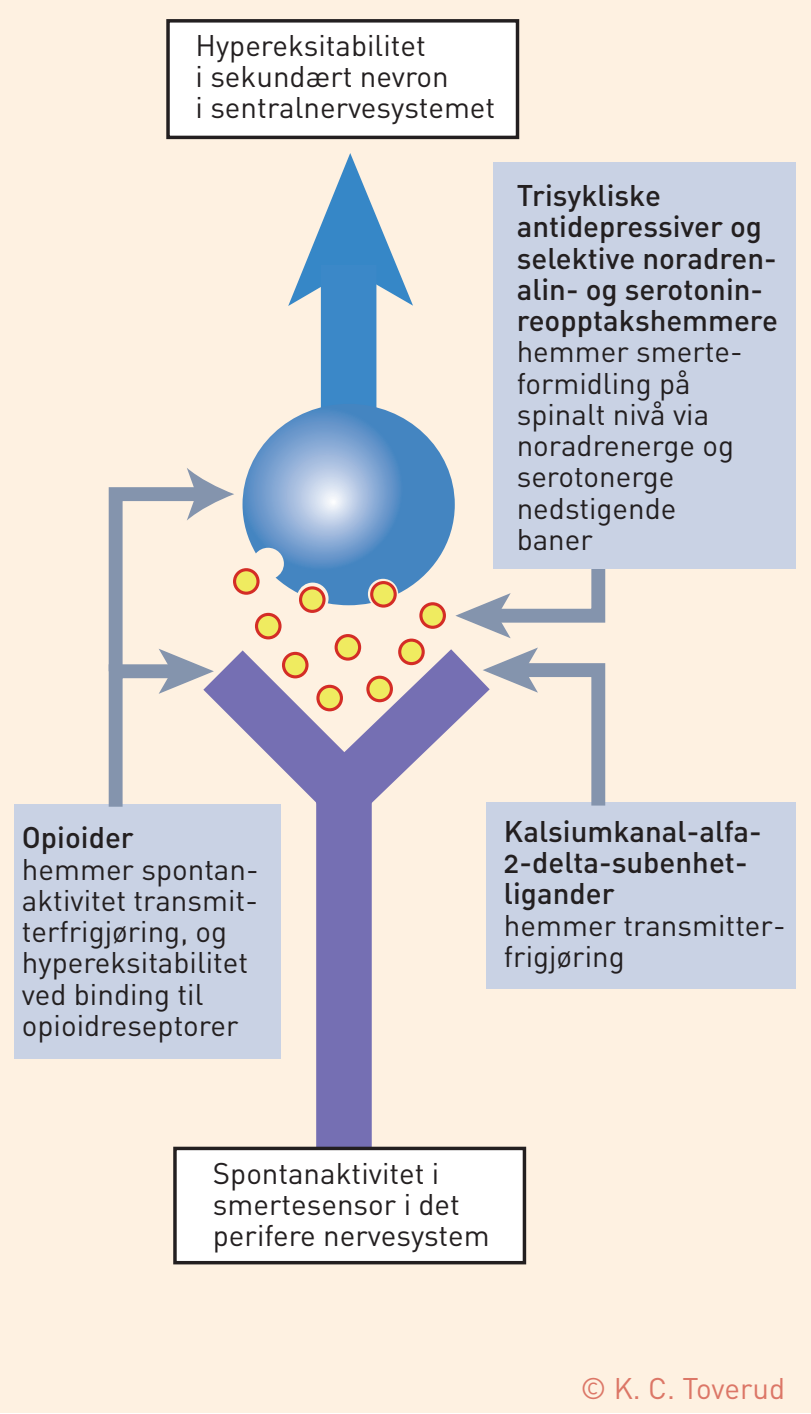

Figur 1 Forenklet beskrivelse av hvordan medikamenter anbefalt i retningslinjene (1-8) reduserer nevropatisk smerteformidling. Flere angrepspunkt (noen felles) og manglende selektivitet for deler av nervesystemet gjør at medikamentene også påvirker smerteopplevelsen og ledsagende symptomer. Manglende selektivitet og effekter i andre organer gir bivirkninger. Kunnskap om betydning av de enkelte angrepspunkt for smertelindring er ufullstendig

resultatene også gjelder ved langtidsbehandling. Det er også mangel på studier der man sammenlikner effekt av legemidler eller vurderer nytte av kombinasjonsbehandling (6). For å sammenlikne effekt og rangere legemidler brukes ofte antall pasienter som må behandles for at én skal bli frisk (number needed to treat (NNT) som effektmål. Her defineres det som antall pasienter som må behandles for å gi en pasient mer enn $50 \%$ smertereduksjon (korrigert for placeboeffekt). Ideell NNT er 1, men ved nevropatisk smerte er 2-6 vanlig $(6,8)$. Forskjellig design i eldre og nyere studier, inkludert ulik terskel for smertereduksjon og bruk av for lave doser, begrenser imidlertid nytten av dette effektmålet som sammenlikningsgrunnlag (1). Vanligvis vil $\leq 50 \%$ av pasientene oppnå tilfredsstillende smertelindring (6), bivirkninger er hyppige og rangering av legemidlene etter effekt på smertelindring samsvarer ofte ikke med effekt på livskvalitet (5,
6). Antall pasienter som må behandles i en gitt tidsperiode for at én skal bli rammet av en alvorlig bivirkning (number needed to harm, $\mathrm{NHH}$ ) har begrenset nytte som sikkerhetsmål fordi bivirkninger ikke studeres systematisk og tallet ofte er retrospektivt basert på antall pasienter som ikke fullfører studien (11).

\section{Legemidler og type nevropati}

Figur 1 viser anbefalte legemidler basert på retningslinjene (1-8). Effekter på ledsagende angst, depresjon og søvnløshet har betydning for pasientens smerteopplevelse og livskvalitet. Legemidlene er vurdert etter symptomkontroll og ikke etter effekt på spesifikke smertemekanismer. Risiko for utilfredsstillende smertelindring i tillegg til bivirkninger gjør at det er behov for utvikling av nye, mer effektive og forhåpentligvis sykdomsmodifiserende legemidler (12).

Trisykliske antidepressiver er førstevalg ved flere typer nevropati og viser like god effekt hos ikke-deprimerte som hos deprimerte (3). Både nortriptylin og amitriptylin brukes i Norge, men vi anbefaler fortrinnsvis nortriptylin fremfor amitriptylin, spesielt hos eldre, på grunn av en relativt svak antikolinerg effekt. Amitriptylin har erfaringsmessig mer sedativ effekt og er et alternativ som kan doseres om kvelden til pasienter med smerte og innsovningsvansker. Trisykliske antidepressiver må brukes med forsiktighet ved epilepsi og er blant annet kontraindisert ved kjent kardial arytmi.

Gabapentin og pregabalin har i flere studier vist effekt både ved perifer og sentral nevropatisk smerte, men det er også studier som ikke har vist effekt $(3,6,12)$. Det er risiko for seponeringsreaksjoner og misbruk av pregabalin og gabapentin, spesielt sammen med opioider og benzodiazepiner, og ved tidligere rusproblemer (10).

Noradrenalin- og serotoninreopptakshemmere har vist effekt ved flere typer nevropati 
$(3,6)$. En klinisk studie med over ett års åpen fase-forlengelse viser effekt av duloksetin ved smertefull diabetesnevropati (13). Venlafaksin har vist effekt i høy dose ved flere former for nevropati, men ikke ved postherpetisk nevralgi $(3,6)$.

Lokalt applisert lidokain i $5 \%$ oppløsning tolereres godt og har vist effekt ved postherpetisk nevralgi med allodyni, andre typer nevropati med allodyni og ved lokalisert nevropatisk smerte $(2,4,6)$. Lidokain finnes også som plaster som kan være egnet som lokalbehandling.

I retningslinjene anbefales det å vurdere opioider til pasienter som ikke har hatt respons på andre anbefalte legemidler (1-8). Det gjelder spesielt ved akutt nevropatisk smerte eller akutte forverringer av eksisterende nevropatisk smerte, nevropati ved kreft og som adjuvans ved kraftige smerter mens et førstevalg titreres. Nyere kliniske studier med opioider har vist like god effekt som trisykliske antidepressiver og gabapentin, men studiene har kun hatt en oppfølgingstid på 1-8 uker $(2,6)$. Risiko for opioidassosiert hyperalgesi samt avhengighet gjør at opioider ikke er førstevalg. Hvis de skal benyttes, er vår vurdering at det bør være på streng indikasjon og med kortest mulig behandlingstid. Ved akutte tilstander som nevnt ovenfor, anbefaler retningslinjene kortvirkende opioider, mens overgang til depotformulering med lang halveringstid kan være egnet ved kronisk nevropati ved kreft (6). Tramadol har mindre smertestillende potens enn oksykodon, men antas å gi mindre risiko for misbruk (6). Det minnes om at feilbruk av opioider regnes som et problem i behandling av kroniske ikke-maligne smerter (14).

Andre antidepressiver (bupropion, citalopram, paroksetin) og antiepileptika (karbamazepin, okskarbazepin, lamotrigin, topimarat, valproat) har kun vist effekt i noen studier $(2,3)$. De kan være aktuelle til pasienter som ikke responderer eller tolererer første- og andrevalg blant legemidlene (6). Det er også kommet nye legemidler som tapentadol med effekt på opioide og noradrenerge reseptorer, og lakosamid (antiepileptika) som prøves ved nevropatisk smerte (8). I likhet med cannabinoider som nesespray eller til peroral administrasjon er det imidlertid foreløpig begrenset dokumentasjon for effekt og sikkerhet. Intradermal injeksjon av botulinumtoksin kan egne seg ved lokalisert nevropatisk smerte (8).

Ved sentral nevropatisk smerte er det få legemidler som har vist effekt. Trisykliske antidepressiver har best dokumentasjon ved smerte etter hjerneslag, og gabapentin/pregabalin mot smerte ved ryggmargskade (7).

Trisykliske antidepressiver, opioider, gabapentin og pregabalin har vist relativt lik smertestillende effekt ved de fleste typer nevropati, med unntak av trigeminusnevralgi, kronisk radikulopati, hivnevropati og cytostatikaindusert nevropati (12). Karbamazepin regnes som et førstevalg ved trigeminus- nevralgi, men man må være oppmerksom på at medikamentet har interaksjoner med andre legemidler (6). Ved hivnevropati er det kun moderat effekt av lamotrigin og capsaicinplaster, men sistnevnte kan egne seg ved postherpetisk nevralgi (6). For alle legemidlene anbefaler vi individuell titrering til laveste effektive dose. Autoseponering er ikke uvanlig hvis startdosen er for høy. Vi anbefaler også at maksimal tolerert dose prøves i minst to uker før man skifter til et annet legemiddel. Flere av legemidlene kan gi seponeringsreaksjoner med behov for langsom nedtrapping. Manglende effekt eller bivirkninger bør føre til revurdering av medikamentell behandling i samråd med nevrolog eller annen smertespesialist. Nye studier har vist at kombinasjon av legemidler kan gi bedre effekt på nevropatisk smerte hos noen pasienter, men foreløpig er det begrenset dokumentasjon (7). Vår erfaring er at kombinasjonsbehandling ofte kan forsøkes hos de dårligste pasientene. Ulempen er at kombinasjonsterapi ofte gir risiko for interaksjoner, bivirkninger og økte kostnader. Legemidlene som omtales i denne artikkelen kan refunderes på blå resept for kronisk smerte etter refusjonskode -71 , enten som forhåndsgodkjent refusjon eller etter individuell refusjon.

\section{Oppsummering}

Medikamentell behandling av nevropatisk smerte er avhengig av type nevropati og eventuelle ledsagende symptomer. I nyere retningslinjer anbefales legemidler med dokumentert symptomkontroll i kliniske studier, men nevropatisk smerte er vanskelig å behandle, og vår erfaring er at det ofte vil være behov for individuell tilpasning. Vi trenger mer effektive og trygge legemidler til denne pasientgruppen.

Geir D. Slapø (f. 1961) er spesialist i nevrologi og master i helseadministrasjon. Han er avtalespesialist med Helse Sør-Øst.

Forfatter har fylt ut ICMJE-skjemaet og oppgir ingen interessekonflikter.

Jan Schjøtt (f. 1956) er spesialist i klinisk farmakologi, overlege og leder for Regionalt legemiddelinformasjonssenter, Helse Vest (RELIS Vest). Han er professor II i farmakologi ved Klinisk institutt 2, Universitetet i Bergen. Forfatter har fylt ut ICMJE-skjemaet og oppgir ingen interessekonflikter.

\section{Litteratur}

1. Finnerup NB, Otto M, McQuay HJ et al. Algorithm for neuropathic pain treatment: an evidence based proposal. Pain 2005; 118: 289-305

2. Moulin DE, Clark AJ, Gilron I et al. Pharmacological management of chronic neuropathic pain consensus statement and guidelines from the Canadian Pain Society. Pain Res Manag 2007; 12 : $13-21$

3. Dworkin $\mathrm{RH}, \mathrm{O}^{\prime}$ Connor $\mathrm{AB}$, Backonja $\mathrm{M}$ et al. Pharmacologic management of neuropathic pain: evidence-based recommendations. Pain 2007 132: $237-51$.
4. Acevedo JC Amaya A Casasola $\mathrm{OL}$ et al Guidelines for the diagnosis and management of neuropathic pain: consensus of a group of Latin American experts. J Pain Palliat Care Pharmacother 2009: 23: 261-81.

5. Attal N, Cruccu G, Baron R et al. EFNS guidelines on the pharmacological treatment of neuropathic pain: 2010 revision. Eur J Neurol 2010; 17: 1113-23.

6. O'Connor AB, Dworkin RH. Treatment of neuropathic pain: an overview of recent guidelines. Am J Med 2009; 122 (suppl): S22-32.

7. Dworkin $\mathrm{RH}, \mathrm{O}^{\prime}$ Connor $\mathrm{AB}$, Audette J et al. Recommendations for the pharmacological management of neuropathic pain: an overview and literature update. Mayo Clin Proc 2010; 85 (suppl): S3-14.

8. de Leon-Casasola O. New developments in the treatment algorithm for peripheral neuropathic pain. Pain Med 2011; 12 (suppl 3): S100-8.

9. Treede RD, Jensen TS, Campbell JN et al. Neuropathic pain: redefinition and a grading system for clinical and research purposes. Neurology 2008; 70: $1630-5$

10. Jørum E. Utredning av nevropatisk smerte. Tidsskr Nor Lægeforen 2005; 125: 2652-4.

11. Gabapentin and pregabalin: abuse and addiction. Prescrire Int 2012; 21: 152-4

12. Finnerup NB, Sindrup SH, Jensen TS. The evidence for pharmacological treatment of neuropathic pain. Pain 2010; 150: 573-81.

13. Raskin J, Smith TR, Wong K et al. Duloxetine versus routine care in the long-term management of diabetic peripheral neuropathic pain. J Palliat Med 2006; 9: 29-40

14. Jørum E, Warncke T. Behandling av kronisk ikkemalign smerte. Tidsskr Nor Legeforen 2012; 132 2474

Mottatt 10.2. 2012, første revisjon innsendt 30.6. 2012, godkjent 21.3. 2013. Medisinsk redaktør Merete Kile Holtermann. 